\title{
Recession forces Japanese industry to cut back on support of universities
}

Tokyo. Just as Japan's cash-starved universities were anticipating extra money from the government (see Nature 360, 8; 1992), another source that has helped them to weather bad times over the past decade seems about to become a victim of the recession.

The 2 November issue of Nikkei High Tech Report, an industry newsletter, reports that companies are beginning to freeze donations to universities and to reduce joint and commissioned research with university researchers. Over the past ten years, with the encouragement of the government, donations from Japanese companies have risen steadily and now stand at nearly $¥ 50$ billion ( $\$ 416$ million) a year (see figure). That is almost as much as universities receive for competitive research grants from the Ministry of Education, Science and Culture.

There has been a similar surge by industry in supporting joint and commissioned research with universities, although the total is only about a quarter of spending on donations. Furthermore, during the past six years the education ministry has set up 28 joint research centres on university campuses with lavish facilities to encourage collaborative research with local industry (see Nature 348, 7; 1990).

The donations, which constitute by far the largest contribution from industry, consist of vast numbers of awards ranging from a few hundred thousand to a few million yen (about $\$ 1,000$ to $\$ 10,000$ ) to individual professors. Most of the money goes to researchers in engineering faculties rather than those involved in basic research. Although the donations are small, the money does not come with the same red tape that accompanies government grants. And a few prominent professors are supported by dozens of companies.

Nikkei High Tech Report found that Tokyo Institute of Technology, Japan's leading national university for industry-related research, received 2.16 billion in donations in 1991, about 5 per cent of all donations to Japan's 98 national universities. That figure rose by 20 to 36 per cent each year between 1988 and 1991. However, in the first seven

\section{More - but for how long?}

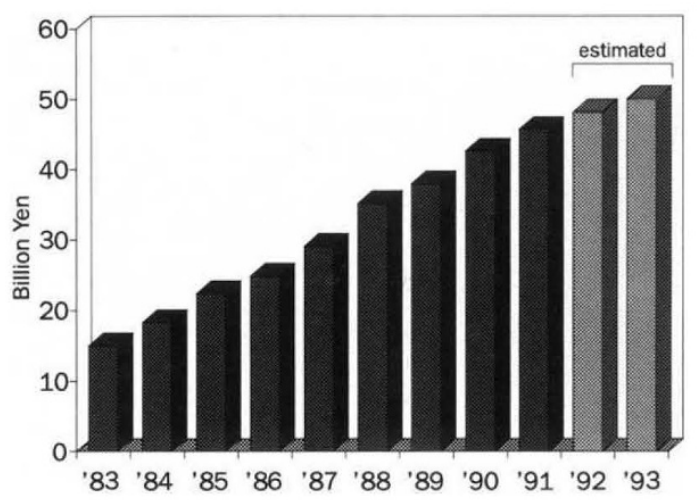

months of this fiscal year, which began on 1 April, the institute received only $¥ 1.16$ billion, and there will be little if any growth for the entire fiscal year if donations continue to come in at the same rate.

An education ministry official disputes the Nikkei report, saying that generalizations cannot be made on the basis of the figures for one institution and that many companies make donations only in the latter half of the year. But he says that the ministry does not expect the growth in the donation budget to be as rapid as in recent years.

A researcher at one of Japan's leading electronics manufacturers, on the other.hand, says the newsletter report is "absolutely correct". His company is reducing its donations because the sums are "so huge", he says, and because the company's research budget is being squeezed by the recession. It

\section{How not to brave the cold}

Tokyo. The squeeze on research budgets in Japan's electronics companies (see above) has led to some bizarre cost-cutting measures that have backfired.

Earlier this year, Toshiba Corporation switched off the heating during the lunch hour to reduce the company's electricity bills. But chilly Toshiba researchers brought in small electric heaters and the company's electricity bills soared.

Another company tried to save money by stopping the issue of business cards to its researchers. But employees, concerned that without a name card they would cease to exist, diligently photocopied their remaining cards. The resulting increase in copying and paper costs more than offset any savings.

D.S. is now almost impossible to recommend new funding for a university research group, he says, regardless of its quality.

The situation is not uniform across industries. Last week, 17 electronics companies reported the effect of reduced consumer demand in the first six months of the year, with Fujitsu's profits down more than 20 per cent and those of Mitsubishi Electric and NEC by nearly 30 per cent. Many electronics companies have frozen operating budgets for research and slashed budgets for buying research equipment, particularly in areas that are furthest from developing products.

In other industries, such as the pharmaceutical industry, the situation is brighter. "People have to continue buying drugs even in a recession", says one researcher from Takeda pharmaceutical company. And a professor involved in marine biotechnology research at one of Japan's national universities says that he has seen no reduction in the generous donations he gets from various industries.

The education ministry remains optimistic, opening five more joint research centres at universities and predicting a modest increase in donations from industry in 1993.

David Swinbanks

\section{NSF commission affirms importance of basic research}

Washington. The US National Science Foundation (NSF) should continue to focus on basic academic research while also supporting projects that could benefit society directly, according to members of the Commission on the Future of the NSF who attended the group's final meeting last weekend. The 15 -member commission also agreed with a proposal written by member John Armstrong of IBM that the NSF should consult more often with those in the commercial sector before deciding how to spend its research dollars.

Congress has asked NSF to demonstrate its commitment to converting basic research into products in an explanation due next month of its current budget, and some of the commission's recommendations are expected to be incorporated into that document. The commission expects to deliver its report on 20 November to the National Science Board, the NSF's governing body.

Traci Watson 